\title{
THE EPIDEMIOLOGY OF ISCHAEMIC HEART DISEASE
}

\author{
By B. BRonte-STewart, M.D., M.R.C.P. \\ Clinical Nutrition Research Unit, Department of Medicine, University of Cape Town
}

The comparison of the behaviour of disease at different times and between different places contributed largely to the elucidation of the causes of the infectious fevers. The extension of the epidemiological method of study to certain noninfectious disorders is already showing its benefit. It was largely due to this form of investigation that few will now uphold the view that ischaemic heart disease* is merely a natural sequence of the ageing process. With this comes great hope that one of the greatest menaces in our prosperous Western civilization may eventually be controlled and prevented.

The epidemiological characteristics of ischaemic heart disease can be outlined as follows:-

I. Increasing Mortality. In most parts of the British Commonwealth, North America and other Western industrialized areas, ischaemic heart disease is one of the commonest causes of death, yet before 1920 the disease was a rarity: for example, in Britain during 1956 over 45,000 males died from this cause, yet in 1921 the figure was only 743. Improvements in diagnosis and age survival, while they probably contribute, can hardly account for the fact that over the last io to I 5 years the age-standardized death rate has been doubled, and at some ages even trebled (Martin, 1956).

2. Sex Factors. Certainly in the younger age groups a striking sex difference in the mortality of the disease exists. This difference is less remarkable after the menopause, and the increased frequency of the disease in women following artificial menopause presumes that this relationship is determined by the sex hormones. It must be emphasized, however, that the sex difference in mortality does not reach unity even in the seventh decade. Other points worthy of note are that this sex difference is greatest in countries where a high

* 'Ischaemic heart disease' is defined as the cardiac disability, acute and chronic, arising from reduction or arrest of blood supply to the myocardium in association with disease processes in the coronary arterial system. (World Health Organization, 1957.) degree of susceptibility to the disease exists and is not remarkable in those areas where the disease is rare (Walker et al., 1956; Keys, 1956a). The two-fold and three-fold increase in death rate referred to above applies equally to the female sex, but in the younger groups, as the disease has become more frequent, the sex ratio has increased (Martin, 1956). At given age, the female death rate in a highly susceptible area exceeds that of the male from a low-susceptibility group.

3. Inter-racial Differences in Prevalence of Ischaemic Heart Disease. At the one extreme lie the Japanese resident in Japan and the Bantu resident in Africa, in whom the disease is a rarity, while 2 the other extreme are the people of the Unite States of America, the White population of Sout Africa, Canada, Australia, New Zealand, Finlan and Great Britain (Fig. I). The remaining Scandinavian countries form an intermediate group with the Federal Republic of Germany, the Netherlands, and the Jewish population of Israel, whilst the disease appears to be of low frequency in France, Italy, and many countries on the Mediterranean littoral (World Health Organization, I956).

4. Intra-racial Differences in Prevalence. Within an apparently homogeneous racial group, different degrees of susceptibility are seen. Japanese who have migrated to live under the American mode of life in Hawaii and the United States have a far greater mortality than those Japanese who remained in Japan (Keys et al., 1958). Similar differences are reported on Jews in Israel (Toor et al., 1957). The occupational mortality statistics (Registrar-General, 1954) for the ro-year period ending $195^{\circ}$ illustrate the greater susceptibility of the professional and executive classes in England and Wales (Table). A similar trend is seen in retired men and their wives, once over 65 years of age. Rich men are held to be more susceptible than poor men in Madrid (Keys, 1956b), and similar differences in other areas point to a factor related to prosperity. In many countries subjected to the deprivations of the I939-I945 war, 


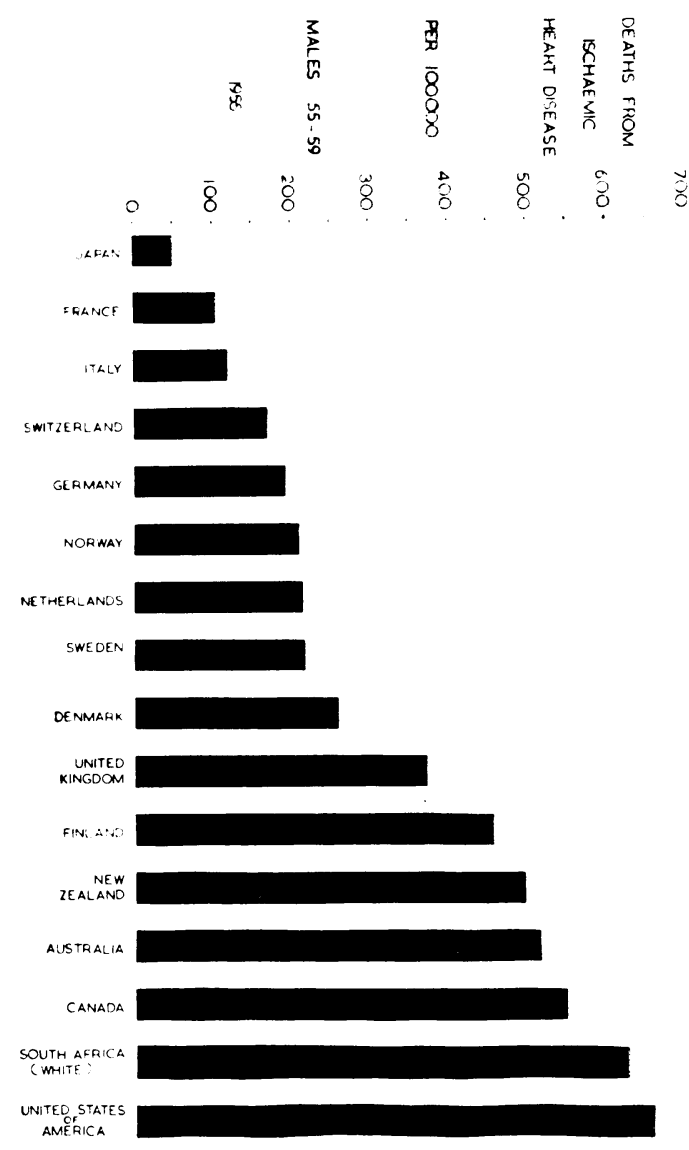

FIg. 1.-Mortality ischaemic heart disease, 1955. (International Classification No. 420), for men aged 55-59 years. (World Health Organization, 1956$.

notably Norway (Str $\phi \mathrm{m}$ and Jensen, r95 I), Sweden (Malmros, I 950), and Finland (Vartiainen and Kanerva, I947), a sharp decrease in mortality from circulatory disease occurred. In Finland, the amount of atherosclerosis during this period was less than that before the war. Following the end of the war the death rates continued to rise.

\section{Interpretation of Epidemiological Data}

The epidemiological method, however, is not without its hazards, and the data as presented are vulnerable to misinterpretations. The reliability of epidemiological data depends in large measure upon the accuracy with which the prevalence of the disease can be measured. Standardization of the criteria for such measurement becomes essential if comparisons are to be made in the behaviour of the disease between different times, between different places, and especially where different investigators are involved.
There are two epidemiological indices available for the measurement of morbidity and mortality. The prevalence or the proportion with ischaemic heart disease at a given time is a ratio of those afflicted to the population at risk. Errors, therefore, may arise in both numerator and denominator of this ratio, i.e. not only in the identification of ischaemic heart disease but also in the sampling and definition of the population from which they are drawn. By virtue of the fact that the disease is more common in males, and more frequent in the elderly, differences between areas could arise from differences in the age and sex composition of the populations at risk. The prevalence, too, would be higher, even holding age and sex constant, in an area to which those crippled by the disease are attracted for climatic or other reasons to retire. For the same reason, any data based on hospital admissions or autopsies are suspect, in that they would be derived from highly selective groups dependent on the pattern of disease in the subtending community, apart from the attitude adopted towards post-mortem examinations and the frequency with which they are done.

An estimate of prevalence is a necessary preliminary for the alternative index, the incidence (inception rate or attack rate) which measures the rate of appearance of the disease in the community. This needs a detailed follow-up of a welldefined, large, and fully examined population and is, therefore, more expensive and more difficult. Bias could be introduced by a high rate of refusal to co-operate and the population under study, if not sampled at random, need not represent the whole community from which they are drawn (Thomas et al., 1958).

One of the greatest difficulties confronting epidemiologists in the further study of ischaemic heart disease, is the lack of any reliable measure of the presence or development of the disease in the living. Even in the dead there are many fallacies in the use of national vital statistics or autopsy data. Differences could result from improvements in diagnostic facilities, changing fashions in diagnosis, the accuracy of death registration and changes in definition, nomenclature and coding.

Ischaemic heart disease, by its very nature, magnifies these difficulties. Its development may be insidious, or so abrupt that the victim would have been passed as normal by every known test immediately prior to its onset. The disease, furthermore, once fully developed has a protean manifestations. Even myocardial infarction may be painless and clinically may go unrecognized (Paton, 1957). Recovery from myocardial infarction may be complete and leave no detectable residua. The similarity of the clinical syndrome 
with that of pulmonary embolism and idiopathic pericarditis adds to the possibility of error in clinical diagnosis. Considerable controversy exists as to the underlying pathology, yet on many occasions estimates of prevalence have been made on the severity of atherosclerosis of the arterial system and, in certain of these claims, no attention has been paid to the possibility that the degree of atherosclerosis of the aorta need not parallel that of the coronary arteries (Elkeles, 1957; Epstein, 1957). Furthermore, it is well recognized that severe coronary atherosclerosis may be present without any detriment to health in the living, or signs of myocardial damage in the dead. Of greater concern, however, is the considerable proportion of cases of frank myocardial infarction where no subtending occlusion, whether it be thrombotic or atherosclerotic, can be shown to have occurred (Branwood and Montgomery, 1956). Minor differences in prevalence should be viewed in this light.

There are few, however, with ordinary clinical experience who would doubt the fact that ischaemic heart disease has increased remarkably in frequency and is affecting younger and younger age groups. There are few, too, who would submit differing diagnostic standards or changes in the age and sex composition of the population at risk as the reason for the year by year increase in mortality. In neighbouring countries, and in countries where a similar standard of diagnosis and similar age/sex structure of the population at risk should exist, major differences in death rates exist. For example, Norway, Sweden and Denmark have less than half the death rate of Finland. The death rate for American males aged 55 to 59 years is 660 per 100,000, whereas that for England and Wales is 379 (Fig. I). In Japan this figure is 50 and, as a recent visit showed, there is no doubt that the disease there is extremely infrequent. Although the difficulties aforementioned in interpretation of epidemiological data may influence one's interpretation where small differences are reported, these large differences resist such an easy explanation.

\section{Heredity versus Environment}

An easy explanation for these wide inter-racial differences would be that the disease is genetically transmitted. With the exception of Finland, those countries with the highest death rates are peopled mainly by those of Anglo-Saxon stock. Ischaemic heart disease is a common accompaniment of certain diseases, probably genetically transmitted, viz. xanthomatosis and diabetes mellitus. In fact, for many years the view was held that survival from ischaemic heart disease was determined largely by the inherited coronary arterial tree.

Probably the greatest single contribution of significance that drew attention to the role of environmental factors, if not wholly, then in part, was the temporary drop in mortality during the 1939-1945 war in many European countries. This, together with the sharp increase in death rate recently, the differences between racial groups depending on their migration, and other epidemiological features, point to some factor or factors in the mode of life that is accelerating its development. This influence appears to accompany prosperity, particularly within our Western civilization, and is operating with increasing frequency over the last 20 to 30 years.

This era has seen a vast change in our mode of life. There is less poverty, with better housing facilities, a decreased exposure to infection with, $\frac{\vec{C}}{8}$ possibly, changes in the intestinal flora, a factor as yet unstudied in this disease. One has witnessed the growth in popularity of the automobile, the telephone, radio and television. There is a greater tendency towards more sedentary forms of occupation and relaxation. An increasing number have to bear some form of supervisory responsibility. There have been changes in our diet, and a rise in tobacco consumption in the form of cigarette smoking has occurred. Many of these environmental factors are extremely difficult to measure, but amongst them may lie the reasons for the marked increase in mortality from ischaemis heart disease.

\section{Physical Activity}

Gertler and White (1954), in their study of $\frac{2}{D}$ ischaemic heart disease in young adults, were impressed with the frequency with which the disease manifested itself in men who had been vigorous athletes in their youth and had failed to maintain this high level of physical activity. The occupational mortality figures of the Registrar-General (I954) (Table), show a trend that could easily be attributed to lack of physical activity. Unfortunately, in most instances, those in the more sedentary occupations are the more prosperous of the community, so that other variables are at play.

Table-Standardized Mortality Ratios of Men Aged 20-64 (1940-1950) Great Britain

\begin{tabular}{l|l|l|l|l|l|}
\hline & & Social Class \\
\hline Ischaemic heart disease & I50 & II & III & IV & V \\
\hline
\end{tabular}

Occupational mortality trends in ischaemic heart disease extracted from Decennial Supplement, 195 I (Registrar-General, 1954). Constitution of the social classes is as follows:-

(I) Professional, etc.; (II) Intermediate; Skilled. (IV) Partly skilled; (V) Unskilled occupati) Mortality without regard for occupation equals 100. 
There are other difficulties in regard to assessing physical activity in occupation. The measure of physical activity during leisure hours is not easy and there are such matters as occupational preselection. This latter has been brought to the fore by Morris's (1956) re-analysis of the data presented in 1953 (Morris et al., 1953). It had been shown, for example, that the attack rate and severity of ischaemic heart disease appeared to be greater in London bus drivers than in the doubledecker bus conductors. This was attributed to the greater physical activity of the bus conductors, but on subsequent analysis (Morris, 1956) based on uniform sizing, it was found that there is a difference in physique between drivers and conductors, indicating the possibility of a genetic difference. Such work, although of great interest and importance, is fraught with these difficulties. It is known that the onset of myocardial infarction is preceded as often by sedentary. activity as by moderate to severe exercise, and it seems improbable that exercise could be the major explanation for the marked differences in reported mortality in neighbouring countries in Europe.

\section{Posture}

It is well recognized that local factors within the circulatory system may determine the distribution and severity of the atheromatous lesions. The frequency with which lesions are seen in the femoral arteries in Hunter's canal has been attributed to the pull of the adductor fascia (Dunlop and Santos, 1957) and similarly the role of cervical spondylitis in vertebral artery atheroma has been emphasized (Hutchinson and Yates, 1956). Could local factors account for the increasing incidence of ischaemic heart disease? It has been suggested. (Stewart, 1957) that the frequency with which the descending branch of the left coronary artery was involved was due to slouching in easy chairs, allowing the abdominal contents to exert pressure upwards on the posterior part of the diaphragm which, in turn, caused anterior kinking of the heart. Another possible explanation becomes available for the driver-conductor differences referred to above, and for the fact that Yudkin (1957) could correlate best the increase in death rate over the last 30 years in England and Wales with the increase in numbers of radio and television licences.

\section{Mental Stress}

This is an exceedingly difficult factor to measure. It would be relatively easy to absolve this as a major factor with the argument that the incidence of the disease fell during the war years in Europe. There are few, too, who would claim that the poverty-stricken are less subject to mental stress than the oft-dramatized picture of the American tycoon or of others with supervisory responsibility. Mental stress, however, may operate in more complex ways. It does not follow that the reactions to acute intermittent stress are similar to those of chronic, prolonged mental strain. For example, intermittent stress in negotiating traffic could be yet another factor in the data of Morris et al. (1953). Any elevation of the blood pressure is known to accentuate grossly the severity of atheroma in the cholesterol-fed animal (BronteStewart and Heptinstall, 1954) and for this effect, only intermittent elevations of short duration are necessary (Wilens, 195I). Recent work, too, in America, has shown marked changes in serumcholesterol levels during periods of 'deadline' work or other particularly stressful times (Hammarsten et al., 1957; Wertlake et al., 1958). It should not be forgotten that emotional stress has a direct effect on one of the clinical manifestations of ischaemic heart disease, angina pectoris. There is, therefore, sufficient evidence to warrant further investigation on this score.

\section{Tobacco Consumption}

During a study on lung cancer, as an incidental finding Hammond and Horn (1954) reported an association between the amount of tobacco smoked as cigarettes and risk of dying from ischaemic heart disease. Shortly thereafter, a similar graded association was shown to exist in Britain (Doll and Hill, 1956). Pipe and cigar smokers did not appear to have a significantly increased mortality. A considerable change in the manner of tobacco consumption has occurred over the last 30 to 40 years. At the turn of the century there were few cigarette smokers and the increase in number since then could be shown to parallel the increasing incidence of ischaemic heart disease.

Other epidemiological data on cigarette smoking are now becoming available, and there is no doubt that some correlation exists among the 16 countries for which there are records available on death rates and smoking habits (Todd, 1957). On the one hand, the correlation could be interpreted in the manner that heavy cigarette smoking is an Anglo-Saxon habit, because it is highest in the countries in the British Commonwealth and the United States of America. Finland, with a high death rate from ischaemic heart disease, has a cigarette consumption not much greater than Switzerland or Japan, while the last-mentioned country has a $5^{\circ}$ per cent. higher cigarette consumption than either Norway or Sweden, with only a quarter of the death rate.

It is conceivable that both heavy cigarette smoking and ischaemic heart disease are not cause and effect and each may be related in turn to a 
third common factor, such as a sedentary occupation, hyper-excitability or undue tenseness, the level of the blood pressure, or even the diet.

In an inter-racial survey in Cape Town, certain characteristics of men with different smoking habits were studied. Firstly it should be mentioned that cigarette smoking was of similar frequency in the Cape Coloured as in the European groups, but the mortality and morbidity from ischaemic heart disease is vastly different between these two groups (Vogelpoel and Schrire, r955). In this survey it was found that heavy cigarette smokers amongst these apparently healthy men, irrespective of their racial origin or economic class, possessed a cholesterol distribution between the lipoprotein pattern, simulating that expected in patients with ischaemic heart disease. Attention was paid to the frequency with which each smoking group was represented within sedentary occupations as well as the level of the casual blood-pressure, obesity and body configuration, and the diet. The only consistent difference found was that the heavy smokers consumed more fat in their diets than the non-smokers. It was suggested that possibly heavy smoking dulls the palate to the extent that more spicy and savoury foods are chosen, and that the relationship to ischaemic heart disease could operate through the dietary-fat mechanism (Bronte-Stewart, 1956). Further evidence is obviously desirable, but at present it would appear that either a third and common factor links both or that heavy cigarette smoking operates through an accessory mechanism, as yet undisclosed.

\section{Diet}

There has been a major change in our dietary habits over the last few decades. A more universal prosperity has allowed more the opportunity for over-indulgence in many articles of our diet. The most popular hypothesis at present incriminates the dietary-fat intake, in particular the nature of the fatty-acid intake. The evidence for this, although purely circumstantial, is very strong as it can adequately explain, more than any other factor in our present mode of life, not only the epidemiological trends but also the biochemical features of the disease; in addition, it forms a link with animal experiment. This has been the subject of many recent reviews (Bronte-Stewart, 1958) and will be expounded further elsewhere (Brock, r959).

It should be emphasized, however, that many other changes, some subtle, have occurred in our diet over the last four decades. Programmes in industry, agriculture and animal husbandry, have led to changes in food production and manufacture. There has been a greater priming of beef, an increased use of oestrogen implants, stall feeding, synthetic foodstuffs and pre-mix methods of feed- $\frac{2}{z}$ ing. Various techniques have been devised for the preservation of foodstuffs over long periods, as, $\stackrel{c}{c}$ for example, antibiotics for fish and meat, and hydrogenation processes for oils and fats, while $\stackrel{\vec{S}}{+}$ canned goods have become more freely available. These changes have affected all age groups. 흠 Education programmes have instilled into mothers that the greater the weight gain, the healthier the $\stackrel{\mathbb{D}}{\circ}$ infant will be. Forced feeding with compulsory is school meals is practised in areas where the nutritional status of the children is usually more than adequate. Eating habits, too, have changed. Many more now eat larger meals, particularly larger amounts of fat at a single sitting. Dietary factors other than, but closely associated with, over-indulgence of fat, could be at play.

\section{Conclusions}

Many hazards are encountered in the interpretation of epidemiological data, and although possibly it could still be argued that susceptibility to ischaemic heart disease may be, at least in part, genetically determined, there are few who would deny the existence of an environmental influence in its pathogenesis. This influence is an unfore tunate accompaniment of prosperity, particularly amongst the Western industrialized nations and but for the war years in certain areas in Europe this influence has been operating with increasing effect over the last few decades. Several factors that constitute our present-day mode of life immediately become suspect. Those that are obvious are mental stress, physical inactivity, cigarettesmoking habits and the diet. Some of these are not easily measured, and other factors may still be undisclosed. Amongst factors that are known and measurable, several parallel associations emerge, but parallelism need not indicate causal associations. A third and common factor may exist. Furthermore, many variables are encountered, genetic and environmental, some of which may be impossible to control. Cautious interpretation of epidemiological data on ischaemic heart disease is still necessary and in no instance is present evidence sufficient to incriminate or absolve any one factor as being solely responsible.

There can, however, be no doubt as to the value of the epidemiological method in the further study of this disease. It is a disease of man's later years and man's life span is such that all other methods of investigation must, of necessity, be short-term. Delayed or long-term effects cannot be assessed thereby. Not only does the epidemiological approach provide clues on causation for testing under more stringently controlled conditions, but it provides a background on which the true worth of any hypothesis founded purely on laboratory experi- 


\section{Practical Obstetric Problems (2nd edition) by IAN DONALD \\ M.B.E., M.D.(Lond.), F.R.F.P.S.(Glas.), F.R.C.O.G. \\ Regius Professor of Midwifery, Univensity of Glasgow}

$x v i+712 p p$. 139 illustrations (1959) 55s. net

$v i i i+200 p p$. 76 illustrations, 2 colour plates (1958) 30s. net

Physician, St. Bartholomew's and Brompton Hospitals, London; Honorary Physician to H.M. The Queen

\section{General Pathology}

(2nd edition) Edited by SIR HOWARD FLOREY M.D., F.R.C.P., F.R.S. Professor of Pathology, University of Oxford $x v i+932 p p$. 410 illustrations, 3 colour plates (1958) 84s. net

\section{Fluid Balance in Surgical Practice (2nd edition) by L. P. LE QUESNE}

$v i i i+140 p p$.

42 illustrations

(1957) 20s. net

Assistant Director, Department of Surgical Studies, Middlesex Hospital

Newman Street, London, W.I

ment can be assessed. It remains, too, the final testing ground, through the medium of controlled trial, for any programme aimed at the ultimate control and prevention of the disease.

\section{BIBLIOGRAPHY}

BRANWOOD, A. W., and MONTGOMERY, G. L. (I956), Scottish med. $\mathscr{F} ., 1,367$.

BROCK, J. F. (r959), Postgrad. med. F., 35, 2 r 6.

BRONTE-STEWART, B. (1956), Brit. med. F., ii, 659.

BRONTE-STEWART, B. (1958), Brit. med. Bull., 14, 243.

BRONTE-STEWART, B., and HEPTINSTALL, R. H. (1954), F. Path. Bact., 68, 407 .

DOLL, R., and HILL, A. B. (1956), Brit. med. F., ii, 1071 .

DLNLOP, G. R., and SANTOS, R. (1957), New Engl. F. Med., 256, 577 .

ELKELES, A. (1957), Lancet, ii, 714.

EPSTEIN, F. H. (1957), Ibid., ii, 1232.

GERTLER, M. M., and WHITE, P. D. (1954), ' Coronary Heart Disease in Young Adults: A Multidisciplinary Study, Commonwealth Fund, Cambridge (Mass.), Harvard University Press.

HAMMARSTEN, J. F., CATHEY, C. W., REDMOND, R. F., and WOLF, S. G., Jnr. (r957), Circulation, 16, 890.

HAMMOND, E. C., and HORN, D. (1954), F. Amer. med. Ass., $155,1316$.

HUTCHINSON, E. C., and YATES, P. O. (1956), Brain, 79, 319. KEYS, A. (1956a), Brit. med. F., ii, 98.

KEYS, A. (1956b), f. Chron. Dis., 4, 364.
KEYS, A., KIMURA, N., KUSUKAWA, A., BRONTESTEWART, B., LARSEN, N., and KEYS, M. H. (1958), Ann. intern. Med., 48, 83.

MALMROS, H. (1950), Acta. med. scand., suppl. 246, I 37.

MARTIN, W. J. (1956), Brit. med. F., ii, 1523.

MORRIS, J. N. (1956), Lancet, i, 687.

MORRIS, J. N., HEADY, J. A., RAFFLE, P. A. B., ROBERTS, G. C., and PARKS, J. W. (I953), Ibid., ii, 1053.

PATON, B. C. (1957), Amer. F. Med., 23, 76r.

REGISTRAR-GENERAL (r954), Decennial Supplement England and Wales, I95 I, 'Occupational Mortality,' H.M. Stationery Office, London.

STEWART, I. (1957), Brit. med. F., ii, 237.

STROM, A., and JENSEN, A. R. (I95I), Lancet, i, 126

THOMAS, A. J., COCHRANE, A. L., and HIGGINS, I. T. T (1958), Ibid., ii, 540.

TODD, G. F. (r957), 'Statistics of Smoking,' Research Papers No. I, Tobacco Manufacturers' Standing Committee, London. TOOR, M., KATCHALSKY, A., AGMON, J., and ALLALOUF, D. (1957), Lancet, i, 1270 .

VARTIAINEN, I., and KANERVA, K. (1947), Ann. Med. intern. Fenn., 36, 748 .

VOGELPOEL, L., and SCHRIRE, V. (1955), Lancet, ii, I IO8.

WALKER, A. R. P., ANDERSON, M., and BERSOHN, I. (1956), Brit. med. F., i, 1234.

WERTLAKE, P. T. . WILCOX, A. A., HALEY, M. I., and PETERSON, J. E. (1958), Proc. Soc. exp. Biol. (N.Y.), 97, 163.

WILENS, S. L. (195r), Science, 114, 389.

WORLD HEALTH ORGANIZATION (1956), 'Epidemiological and Vital Statistics Report,' 9, 538, World Health Organization, Geneva.

WORLD HEALTH ORGANIZATION (1957), 'Report of the Study Group on Atherosclerosis and Ischaemic Heart Disease, No. I17,' World Health Organization, Geneva.

YUDKIN, J. (1957), Lancet, ii, 155. 